EA 4272

\title{
Port state control inspections in the European Union: Do inspector's number and background matter?
}

\author{
Armando Graziano* \\ Pierre Cariou**

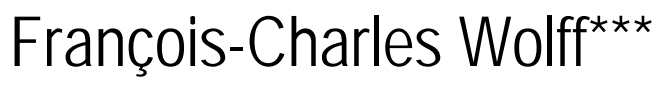 \\ Maximo Mejia* \\ Jens-Uwe Schröder-Hinrichs*
}

\section{$2017 / 15$}

(*) World Maritime University

$(* *)$ Kedge Business School

${ }^{(* *)}$ LEMNA - Université de Nantes 


\section{Port state control inspections in the European Union: Do inspector's number and background matter?}

Armando GRAZIANO (corresponding author), World Maritime University, Fiskehamnsgatan 1, 21118 Malmö, Sweden. Tel: + +46 (40) 356-325. E-mail: agr@wmu.se

Pierre CARIOU, Kedge Business School, 680 Cours de la Libération, 33405, Talence, France. Tel: +33 (0)5 568455 56. E-mail: pierre.cariou@kedgebs.com

Francois-Charles WOLFF, LEMNA, University of Nantes, BP 52231 Chemin de la Censive du Tertre, 44322 Nantes Cedex 3, France ; and INED, Paris, France. Tel: +33 (0)2 4014 17 79. E-mail: francois.wolff@univ-nantes.fr

Maximo Q. MEJIA Jr., World Maritime University, Fiskehamnsgatan 1, 21118 Malmö, Sweden. Tel: $+46-40-356388$. E-mail: mm@wmu.se

Jens-Uwe SCHRÖDER-HINRICHS, World Maritime University, Fiskehamnsgatan 1, 211 18 Malmö, Sweden. Tel: +46-40-3563 88. E-mail: jus@wmu.se 
Abstract. The succession of maritime accidents in the last decades of the $20^{\text {th }}$ Century caused a strong political and public outcry for more stringent maritime safety regulations and measures. One of the most significant developments in this regard was the establishment of several regional agreements on Port State Control (PSC) - the first of which was the Paris MoU - with the specific objective of fighting substandard shipping through coordinated and harmonised inspection procedures. This article is based on results from 32,206 PSC inspections carried out by the European Union and European Free Trade Association Member States within the Paris MoU region from 1 January 2014 to 31 December 2015 to assess whether discrepancies among Member States exist after the entry into force of Directive 2009/16/EC and the introduction of the New Inspection Regime. Further, the study proceeds by investigating whether PSC team composition and inspector's background influence inspection outcomes. The study has identified that differences in detecting at least one deficiency and/or detaining a vessel are significant among Member States. With regard to team composition and background, it appears that the former correlates to the number of deficiencies and detentions and the latter, though the significance is not always consistent, to detecting a certain type of deficiencies according to the specific inspector's backgrounds. The paper concludes by presenting potential policy implications. 


\section{Port state control inspections in the European Union: Do inspector's number and background matter?}

\section{Introduction}

The inspection of foreign flagged vessels in national ports is not a novel exercise. Provisions for the inspection or control of foreign vessels by port states have been a feature of enforcement since the 1929 SOLAS Convention. However, it was not until the emergence of regional agreements - the so-called 'Memoranda of Understanding on Port State Control (PSC MoU)' - that such practice became a regular element in the promotion of maritime safety. As mentioned, "the powers used by Port State Control Officers (PSCOs) are not new; it is the willingness to use the power which is new" $[1, p .1]$.

As often occurs in the policy making process, the catalyst for an increased use of port state control (PSC) is to be found in a series of very serious maritime accidents which occurred in the final decades of the $20^{\text {th }}$ century ${ }^{1}$. These accidents highlighted the unsatisfactory degree of enforcement exercised by certain maritime administration [2-8] and caused a strong political and public outcry for more stringent regulations regarding safety of ships, protection of the maritime environment and living and working conditions $[1,4]$.

In response, eight north European states signed The Hague Memorandum of Understanding (MoU) in 1978, promptly superseded by a more comprehensive gentlemen's agreement in 1982, the Paris $\operatorname{MoU}[7,9,10]$, in order to stem the proliferation of substandard vessels across European waters. The Paris MoU served as the archetype for other MoUs which were established in other regions during the 1990s [10 $]^{2}$. It also served as the backbone for the three PSC Directives adopted by the European Union (EU) since 1995.

\footnotetext{
${ }^{1}$ Amoco Cadiz (1978), Aegean Sea (1992), Braer (1993), Estonia (1994), Erika (1999) and Prestige (2002), among others.

${ }^{2}$ At present nine regional agreements exist: Tokyo MoU (Pacific Ocean), Acuerdo Latino or Acuerdo de Viña del Mar (South and Central America), the Caribbean MoU, the Mediterranean MoU, the Indian Ocean MoU, the Abuja MoU (West and Central Atlantic Africa), the Black Sea MoU, and the Riyadh MoU (Persian Gulf).
} 
The main purpose of regional enforcement is to "drastically reduce substandard shipping in the waters under the jurisdiction of Member States" (MSs) by developing, among other factors "common criteria for control of ships by the port State and harmonising procedures on inspection and detention" [11]. However, issues in the harmonization process have been identified since the emergence of the early MoUs [2, 12-17] that may result in different inspection output, either detentions or deficiencies, depending on the inspecting port authority. Asymmetrical inspecting behaviours can undermine the effective implementation of international regulations $[2,14]$ and distort the level playing field within the region.

This paper inquires into the adequacy in EU Port State controls as reflected by either relative homogeneity or heterogeneity in inspection outcomes depending on where vessels are inspected. For that purpose, the study relies on a dataset from the European Union with detailed records from approximately 48,000 inspections and 130,000 deficiencies detected during the time frame 1 January 2014 to 31 December 2015. A unique feature of the database is that it includes complementary information on the number and background of PSCOs who carried out inspections, giving us the possibility to investigate whether these elements may be correlated to any inadequacies in the PSC inspection regime.

The data was analysed in the following manner. First, an investigation was performed on whether single EU countries record a higher number of deficiencies and detention compared to others. An econometric analysis was used to control for the fact that vessels inspected in different countries do not have the same observable characteristics. Second, an exploration of whether inspection outcomes are correlated to the number and background of PSCOs present on board at the time of inspection was implemented. Overall, the results show that discrepancies in harmonisation have been encountered and that accounting for PSCO's characteristics have an influence on inspection outcomes.

The remainder of the article is organized as follows. Section 2 provides a brief review of the literature concerning PSCs and presents some research hypotheses. In Section 3, a description of the data sample is provided and econometric results are discussed in Section 4. Finally, conclusions and potential policy implications are presented in Section 5. 


\section{Background}

During the first years of its implementation, the Paris MoU underwent some criticisms as it was perceived as a 'discriminatory enforcement' of International Maritime Organization (IMO) conventions [18]. This led several scholars to verify the effectiveness of PSC $[2,4,7,12,13,19-29]$ and its legal foundation [6, 10, 21, 30-34]. According to these investigations, it is nowadays conventional wisdom that PSCS contribute to ensuring compliance with international regulatory efforts $[6-8,19,35]$ and increase safety standards $[5,36]$, pollution prevention and standards for seafarers on board vessels $[20,21]$.

Despite the numerous positive effects observed, even at the early stages of the introduction of regional initiatives on PSC, cross-national differences have emerged in inspection practices and results, whether number of deficiencies or probability of detention. Discrepancies in inspection practices have a profound impact on the credibility of the regional MoUs on PSC. These can distort the market [16] by promoting the so called "port-shopping" phenomenon [10, 14, 21, 35], a strategic practice by some operators who choose certain ports/regions [14, 15] over others because of their less stringent safety enforcement standards. Moreover, differences can undermine the targeting system that relies on the accuracy of inspection results [16]. Reasons for discrepancies can be multiple and diverse.

In the context of international law, an MoU is not a treaty but an administrative agreement $[4,15,37]$ which implies that its provisions are, de jure, non-binding for the signatory parties. In the case of the EU, however, the provisions of the Paris MoU have been made mandatory and enforceable for EU MSs through the issuance of Directive 2009/16/EC. Clearly, an administrative agreement that does not contemplate binding provisions may allow for differences in application while hard law, such as the EU Directive, may presuppose a more harmonised approach.

On a country level, regional differences may be induced by the various stages of development and peculiarities within different regions [12]. Differences across Paris MoU, Tokyo MoU, Caribbean MoU, Viña del Mar Agreement, AMSA and the USCG were identified by Knapp and Franses [16] and Knapp and van de Velden [38]. On a cross-national level, differences were identified within the Tokyo MoU [22], between 
India, Russia and the UK $[2,39]$ and also among Australia, India, South Africa and Russia [17]. However, aside from a recent interview study from Graziano, SchröderHinrichs and Ölcer [40] focusing on discrepancies within the EU region, no empirical study based on PSCs have investigated cross-national differences in the EU following the entry into force of Directive 2009/16/EC.

Considering the reason why discrepancies may appear, Anderson [13] suggested that the lack of appropriate resources and unequal participation of states in the same MoU are factors to be taken into consideration. Anderson [13] also calls into question the diversity in resources, whether manpower, financial, or technological as well as the lack of specific action plans for proper enforcement. Knapp and Franses [16] argue that various port authorities seem to adopt different inspection philosophies in the detention of vessels which translates to perceived cross-national differences.

On a more operational level, ship-related elements play a prominent role on the inspection outcomes. Authors have identified age, ship type, flag of registry as determinants of the number of deficiencies recorded [24]. In spite of the fact that those elements proved to be significant predictors of the inspection results, differences across inspecting authorities, even when controlled for, remain and are still responsible for the number of deficiencies and probability of detentions $[16,17]$. A supplementing conclusion can be reached if considering subjectivity and reliance on professional judgment as inherent contributing elements to cross-national difference $[2,4,40]$. More specifically, some authors have suggested that further investigations should be conducted on the influence that the background of PSCOs and the number of inspectors on the inspection team have on inspections results $[16,41]$.

This paper contributes to the body of literature investigating cross-national differences of PSC practices within the EU as a region. Its first aim is to assess whether particular EU countries record a higher number of deficiencies or higher detention rates. For that purpose, an econometric analysis is applied as there may be differences in the characteristics of the vessel inspected among countries. Following the previous empirical evidence of $[16,17,23,24,28,29,39]$, two research hypotheses are formulated. 
Hypothesis 1. PSCS may lead to country differences both in number of deficiencies and in rates of detention within the $E U$ region even when the characteristics of the fleet inspected are controlled for.

Moreover, in line with $[16,40,41]$, an investigation is performed on whether the number of inspectors allocated for an inspection and the background of inspectors can help in understanding the potential cross-national differences in PSC outcomes.

Hypothesis 2. PSC outcomes can be influenced by the number and background of inspectors within the EU region.

Numerous studies take for granted that the mandatory nature of the European PSC regime, by virtue of Directive 2009/16/EC, translates to a more effective PSC inspection system compared to other PSC MoUs [5].

\section{Data and descriptive statistics}

The hypotheses were tested using PSC inspection data carried out within the EU and European Free Trade Association (EFTA) region within the Paris MoU framework. Originally established in 1982, the Paris MoU includes 27 maritime authorities covering the coastal waters of the European states and the North Atlantic from North America to Europe ${ }^{3}$. These authorities agreed to implement a harmonized system of PSC in the aftermath of the Amoco Cadiz accident in 1978. In this framework, only the 25 EU and EFTA countries belonging to the Paris MoU have been included in the study since they abide by the provisions of Directive 2009/16/EC. Canada and the Russia Federation were excluded from the original dataset.

The selection of vessels to be inspected is based on results from a ship risk profile calculator and a company performance calculator ${ }^{4}$. The influential parameters are the type of ship, whether the ship is older than 12 years, the flag and its performance (from white to black high risk), whether the flag is IMO audited, whether all certificates are issued by flag, the recognized organization and its performance

\footnotetext{
${ }^{3}$ The current member states are Belgium, Bulgaria, Canada, Croatia, Cyprus, Denmark, Estonia, Finland, France, Germany, Greece, Iceland, Ireland, Italy, Latvia, Lithuania, Malta, the Netherlands, Norway, Poland, Portugal, Romania, the Russian Federation, Slovenia, Spain, Sweden and the United Kingdom. For further details on the Paris MoU, see www.parismou.org

${ }^{4}$ These calculators are available online at https://portal.emsa.europa.eu/web/thetis/calculators.
} 
(from very low to high), whether the organization is EU recognized, and the ISM company performance (from very low to high) ${ }^{5}$. The ship risk profile also depends on historical parameters from the last 36 months: at least one inspection, all inspections with 5 or less deficiencies, and number of detentions. A high risk profile is assigned to ships whose score is at least 5 points.

Based on a ship's risk profile, the Inspection and Selection Scheme determines the scope, frequency and priority of inspections. According to the risk profile of ships, the PSC Database THETIS informs the PSC authorities of the priority of a ship entering their ports, whether No Priority (ship should not be inspected), Priority II (PII - ship may be inspected) or Priority I (PI - ship must be inspected). Ships become due for periodic inspection in the following time windows: for high risk ships (HRS), the ship is PII during the first 5 months following the last Paris MoU inspection and PI after 6 months. For standard risk ships (SRS), the ship is PII during 10 months following the last inspection and PI after 12 months. Lastly, for low risk ships (LRS), the ship is PII during 24 months following the last inspection and PI after 36 months.

Each inspection leads to a report, publicly available on THETIS, that includes the following information: date of inspection, type of inspection (initial, expanded, more detailed inspection), country of inspection, ISM company performance, vessel flag of registry, flag performance (white-grey-black list) and risk profile (high, medium, low) ${ }^{6}$. The database also includes information on the year when the vessel was built (from which the age at the time of the inspection is calculated), ship's total length and ship type (general cargo, oil tanker, container, etc). A unique feature of the dataset is that it also includes the inspector's identification number ${ }^{7}$. As discussed later, this will allow to account for the background of inspectors when explaining PSC outcomes. Due to this specific information on inspectors, the various Members States are anonymized in the dataset.

For each inspection, the number of deficiencies and the number of deficiencies leading to detention are reported. The PSC outcomes are defined in the following

\footnotetext{
${ }^{5}$ The International Safety Management (ISM) Code is a mandatory international standard for the safe management and operation of ships and for pollution prevention.

${ }^{6}$ Inspection results can be found at https://portal.emsa.europa.eu/web/thetis/inspections.

${ }^{7}$ Access to the data used in this paper was made possible through an agreement with the EC.
} 
manner. $D E F$ is a binary variable equal to one when following an inspection a specific vessel had at least one deficiency detected (and it is equal to 0 otherwise). DEFN is the number of deficiencies recorded. DET is a binary variable which takes the value of one when a vessel is detained and is equal to 0 otherwise. For each deficiency, each type of deficient or defective item is also recorded.

The empirical analysis is based on an exhaustive dataset provided by the EC with inspection as observation unit. It covers all inspections carried out from January 1, 2014 to December 31, 2015. ${ }^{8}$ Overall, the sample comprises 32,206 PSC inspections. Out of these, 10,076 are initial inspections (31.3\%), 17,431 more detailed inspections (54.1\%), and 4,699 expanded inspections (14.6\%). An initial inspection is a visit on board of a ship in order to check the certificates and documents listed in Annex 10 of the MoU text, the overall condition and hygiene of the ship, if the vessel meets generally accepted international rules and standards and to verify, whether deficiencies found by an Authority at a previous inspection have been rectified. A more detailed inspection is carried out whenever there are clear grounds for believing, during an inspection, that the condition of the ship or of its equipment or crew does not substantially meet the relevant requirements of a relevant instrument. An expanded inspection includes a check of the overall conditions, including human element where relevant, in 14 different risk areas ${ }^{9}$.

Table 1 presents some descriptive statistics of the sample. The proportion of inspections with at least one deficiency is $53.5 \%$. The average number of deficiencies detected during an inspection is 2.4 (with a standard deviation of 4.0). The proportion of inspections leading to detention is equal to $3.4 \%$. As expected, the PSC outcome is strongly affected by the type of inspection. The proportion of vessels with at least one deficiency is $29.3 \%$ for initial inspections, but around $65.0 \%$ for more detailed and expanded inspections. By definition, detention follows a more detailed or an expanded inspection and the conditional detention rate is $5.0 \%$ in both cases.

\footnotetext{
8 In this administrative dataset filled in by maritime authorities, there is no issue of missing data. Data are re-checked by national coordinators once filled in the system. In case of mismatches, the data are verified once more by EMSA personnel dealing with ship inspection support.

${ }^{9}$ See https://www.parismou.org/inspections-risk/library-faq/inspection-types.
} 
Table 1. Descriptive statistics of the sample

\begin{tabular}{|c|c|c|c|c|}
\hline Variables & $D E F($ in \%) & $D E F N$ & $D E T$ (in \%) & Distribution (in \%) \\
\hline \multicolumn{5}{|l|}{ Type of inspection } \\
\hline Initial inspection & 29.3 & 0.7 & 0.0 & 31.3 \\
\hline More detailed inspection & 64.1 & 3.0 & 5.0 & 54.1 \\
\hline Expanded inspection & 66.4 & 3.6 & 5.0 & 14.6 \\
\hline \multicolumn{5}{|l|}{ Type of vessel } \\
\hline Bulk carrier & 54.8 & 2.5 & 3.5 & 18.3 \\
\hline Oil tanker & 39.4 & 1.3 & 1.4 & 7.7 \\
\hline Chemical/gas tanker & 42.9 & 1.4 & 1.5 & 11.3 \\
\hline Containership & 47.6 & 1.7 & 1.6 & 10.8 \\
\hline General cargo & 62.7 & 3.3 & 5.9 & 29.9 \\
\hline Passenger & 58.3 & 2.5 & 1.8 & 2.2 \\
\hline Ro-ro & 52.3 & 2.2 & 2.0 & 7.7 \\
\hline Other & 52.9 & 2.1 & 3.1 & 12.2 \\
\hline \multicolumn{5}{|l|}{ Age at inspection } \\
\hline $0-5$ & 37.8 & 1.1 & 0.9 & 16.5 \\
\hline $5-10$ & 45.9 & 1.6 & 1.9 & 27.1 \\
\hline $10-15$ & 51.4 & 2.0 & 2.3 & 15.6 \\
\hline $15-20$ & 61.3 & 2.8 & 4.1 & 14.7 \\
\hline $20-30$ & 65.5 & 3.5 & 5.7 & 13.5 \\
\hline $30+$ & 71.6 & 4.5 & 8.5 & 12.5 \\
\hline \multicolumn{5}{|l|}{ Flag Performance } \\
\hline White & 51.1 & 2.1 & 2.7 & 91.2 \\
\hline Grey & 69.3 & 4.0 & 8.8 & 4.3 \\
\hline Black medium risk & 82.7 & 5.7 & 12.1 & 2.9 \\
\hline Black medium to high risk & 94.7 & 8.1 & 15.7 & 1.6 \\
\hline All vessels & 53.5 & 2.4 & 3.4 & \\
\hline
\end{tabular}

Source: anonymized data from the EU region 2014-2015, authors' calculations.

Note: $D E F$ is for any deficiency, $D E F N$ is for number of deficiencies, and $D E T$ is for detention.

General cargo is the type of vessel that is the most frequently inspected with $29.9 \%$ of inspections, followed by bulk carrier (18.3\%). There are substantial differences in PSC outcomes depending on the vessel type. There are more deficiencies detected for general cargo (62.7\%), passenger vessels (58.3\%) and bulk carriers (58.3\%). Detention is also much more frequent for general cargo (5.9\%) and to a lesser extent bulk carrier (3.5\%) than for other vessels. The average age of vessels subject to inspection is 15.1 years. There exists a positive correlation between inspection outcomes and age at inspection. Having at least one deficiency is found for $45.9 \%$ of vessels aged between 5 and 10 , but $71.6 \%$ for vessels older than 30 years ${ }^{10}$. In the same vein, flags of registry performance is playing on the likelihood of having more deficiencies and a detention. The average number of deficiencies is 2.1 for the

\footnotetext{
10 The proportion of detained vessels is higher for vessels older than 30 years $(8.5 \%)$ compared to vessels aged between 15 and 20 years (4.1\%).
} 
white category, 4.0 for the grey category, 5.7 for the black medium risk category and even 8.1 for the black medium to high and high risk categories.

To detect potential disparities across the various locations where inspections are taking place, let $n$ be the total number of inspections and $n_{j}$ that for country $j$. The average proportion of vessels with any deficiencies $\overline{D E F}$ for the whole sample may be expressed as:

$$
\overline{D E F}=\sum_{j}\left(\frac{n_{j}}{n}\right) \overline{D E F}_{j}
$$

This corresponds to a weighted sum of the average proportion of vessels with any deficiencies in each country $\overline{D E F}_{j}$.

Figure 1 sheds light on heterogeneity in the number of inspections $n_{j}$ between the various countries and for the 32,306 PSC inspections carried out by the 25 different EU and EFTA countries. Due to anonymization, the various Members States are relabeled using codes ranging from MS1 to MS25. The average number of inspections per country is 1,288 , with a standard deviation of 991. It ranges from 138 (MS11) to 3,520 (MS23). There are large country differences by type of inspections. The average is 403 for initial inspection (with a standard deviation of 339) and 697 for more detailed inspections (with a standard deviation of 546). 


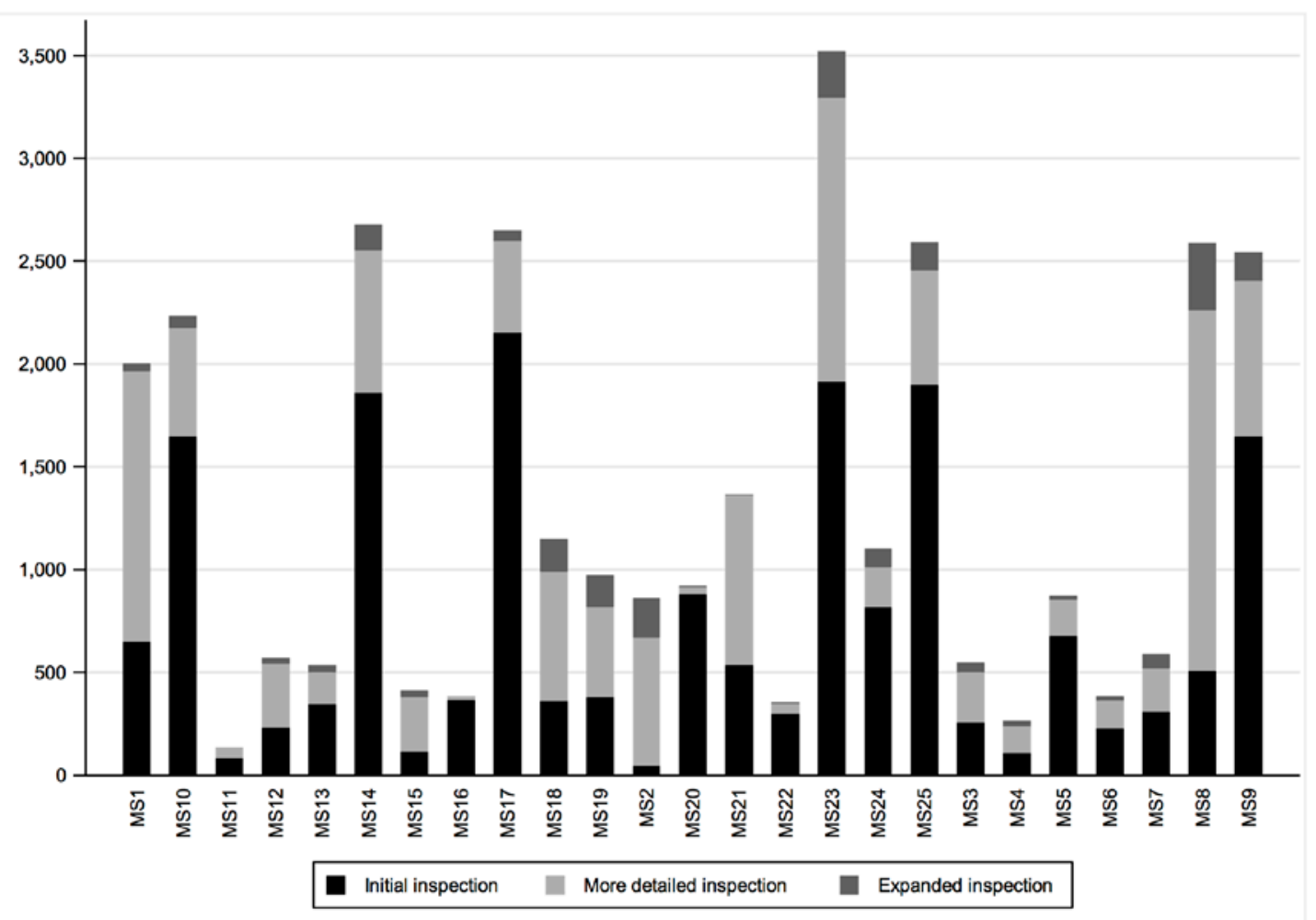

Figure 1. Number of inspections, by member country Source: data from EU region 2014-2015, authors' calculations. Note: MS1-MS25 refer to the different inspection countries.

Figure 2 represents the various PSC inspection outcomes for each member state. The data shows large differences in the region. The average proportion of deficiencies ranges from $69.2 \%$ when vessels are inspected in MS4 to $20.4 \%$ in MS12. This proportion exceeds $60 \%$ in 8 member states (MS4, MS10, MS19, MS2, MS25, MS1, MS21, MS13), while it is below 30\% in 5 states (MS12, MS7, MS6, MS24, MS20). On average, the number of deficiencies per inspection is larger when inspections are carried out in a port located in MS19 (4.2), MS10 (3.8) and MS2 (3.5) ${ }^{11}$. The probability of detention is more likely when inspections are conducted in MS4 (11.8\%), MS10 (6.9\%) and MS11 (6.7\%). Conversely, there is no detention when vessels are inspected in MS6 and MS12. In addition, detentions are not necessarily higher in a country where more deficiencies are detected on average. For instance, in MS11, the detention rate is $6.7 \%$ while the average number of deficiencies is 1.4 .

\footnotetext{
${ }^{11}$ The lowest figures are in MS7 (0.4), MS12 (0.7), MS24 (0.7) and MS6 (0.7).
} 

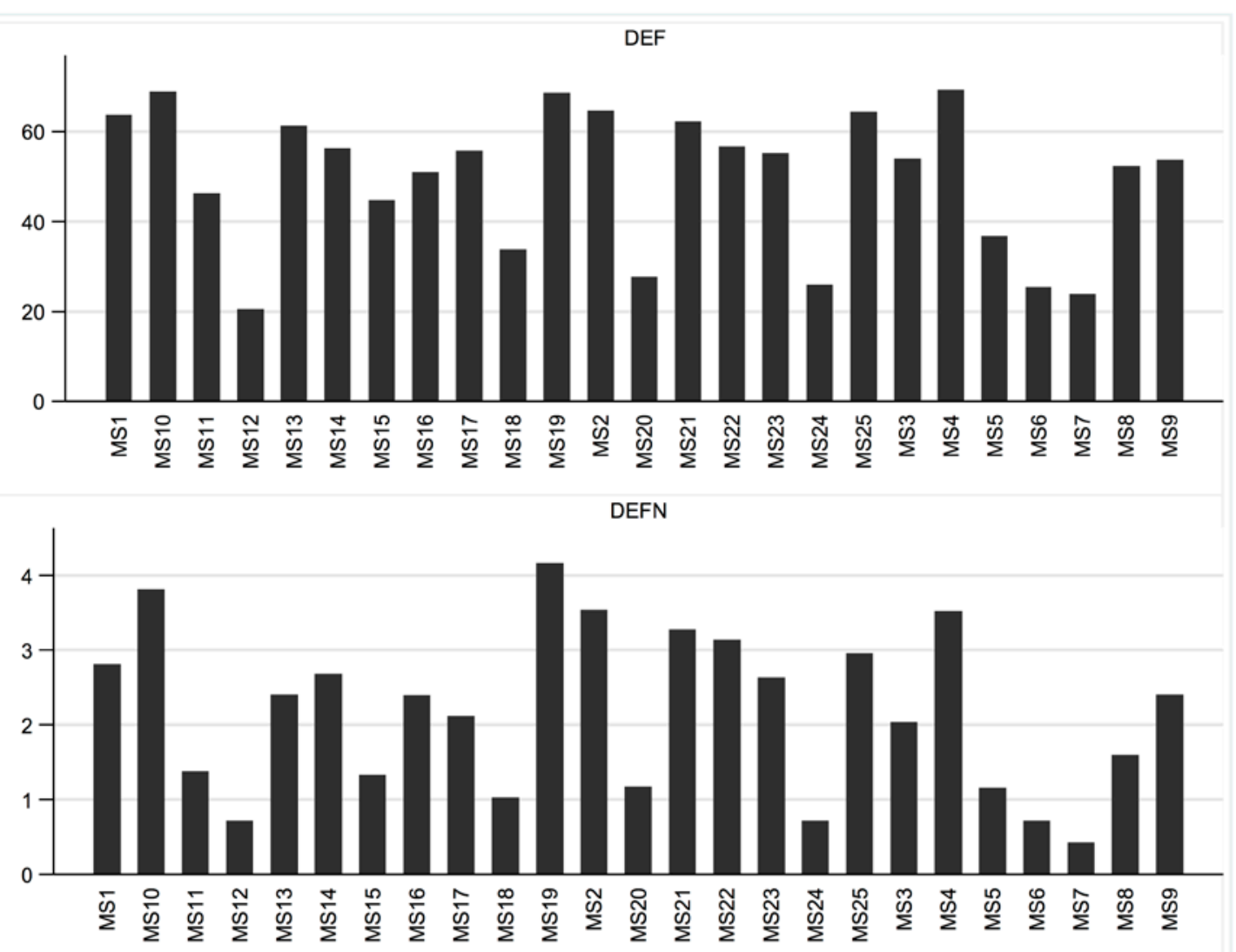

DET

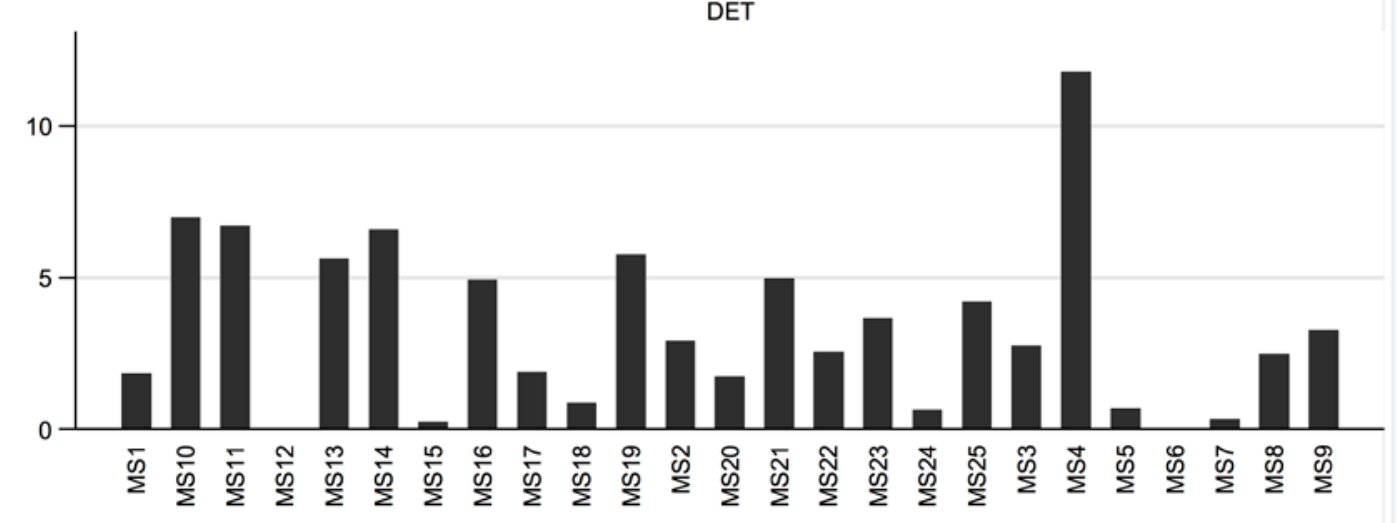

Figure 2. Results of inspections, by member country

Source: data from the EU Region 2014-2015, authors' calculations.

Note: MS1-MS25 refer to the different inspection countries.

From a descriptive viewpoint, a variance decomposition analysis is implemented to assess the extent to which differences in PSC outcomes stem from differences between countries (due to differences in the average outcomes of countries) or differences within countries (due to variation in the outcomes for each country). Let $D E F_{j i}$ a dummy variable indicating whether inspection $i$ occurring in country $j$ leads to the report of any deficiencies. Denoting by $V($.$) the variance$ operator, $V\left(D E F_{j i}\right)$ can be expressed as: 


$$
V\left(D E F_{j i}\right)=V\left(\overline{D E F}_{j}\right)+V\left(D E F_{j i}-\overline{D E F}_{j}\right)
$$

The first term $V\left(\overline{D E F}_{j}\right)$ is the between variance and refers to differences in the average proportion of having any deficiencies between countries. The second-term $V\left(D E F_{j i}-\overline{D E F}_{j}\right)$ is the within variance and corresponds to differences in the PSC outcome observed in any given country with respect to the average level of that country.

For the likelihood of having a deficiency detected, the contributions of the between and within terms to the total variance (equal to 0.248 ) represent $6.4 \%$ and 93.5\%, respectively. Very similar results are found for the number of deficiencies with weights equal to $5.3 \%$ and $94.7 \%$ for the between and within variances, respectively. These findings stress that although there are differences in the average PSC outcomes between countries, there are still large differences in PSC outcomes within each country. This pattern is consistent with two main explanations. On the one hand, there may be some lack of consistency in inspection procedures under the authority of each individual port state. On the other hand, there may be some heterogeneity in vessels calling within each country. In the next Section, the role of vessels' characteristics is taken into account using an econometric analysis.

\section{Results}

\section{Differences by country of inspection}

The average number of deficiencies detected within a given country can be higher if vessels inspected in this country are, on average, in bad condition. To account for this effect on the various PSC outcomes, linear probability models for $D E F$ and $D E T$ and an OLS regression for $D E F N^{12}$ are estimated. In addition to country of inspection dummies, the following list of control variables is included in the various regressions: type of inspection, type of vessel, age at inspection and flag of registry.

\footnotetext{
${ }^{12}$ Similar conclusions were reached using Probit models for $D E F$ and $D E T$.
} 
Table 2 focuses on the influence of country of inspection and reports the corresponding marginal effects for each outcome. ${ }^{13}$

Table 2. Estimates of inspection results - marginal effects for member countries

\begin{tabular}{|c|c|c|c|}
\hline Country of inspection & $D E F$ (in \%) & $D E F N$ & $D E T$ (in \%) \\
\hline MS1 & Ref & Ref & Ref \\
\hline MS10 & $-10.8 * * *$ & $-0.6 * * *$ & $1.7 * * *$ \\
\hline MS11 & $-29.9 * * *$ & $-2.3 * * *$ & 3.3 \\
\hline MS12 & $-48.5^{* * *}$ & $-2.6 * * *$ & $-3.2 * * *$ \\
\hline MS13 & $-11.4 * * *$ & $-1.0 * * *$ & $2.8^{* * *}$ \\
\hline MS14 & $-13.4 * * *$ & $-0.7 * * *$ & $3.3^{* * *}$ \\
\hline MS15 & $-28.6 * * *$ & $-2.3 * * *$ & $-3.5 * * *$ \\
\hline MS16 & $-24.3 * * *$ & $-1.2 * * *$ & 1.6 \\
\hline MS17 & $-11.0 * * *$ & $-0.9 * * *$ & -0.6 \\
\hline MS18 & $-39.3 * * *$ & $-2.5 * * *$ & $-2.3 * * *$ \\
\hline MS19 & $-8.6 * * *$ & $0.3^{*}$ & $1.7^{* *}$ \\
\hline MS2 & $-21.7 * * *$ & $-1.7^{* * *}$ & $-4.8 * * *$ \\
\hline MS20 & $-41.1 * * *$ & $-2.1 * * *$ & $-1.1 * *$ \\
\hline MS21 & $-22.0 * * *$ & $-1.9 * * *$ & $-2.4 * * *$ \\
\hline MS22 & $-14.7 * * *$ & $-0.4^{*}$ & -0.9 \\
\hline MS23 & $-14.2 * * *$ & $-0.6 * * *$ & $0.8^{*}$ \\
\hline MS24 & $-44.7 * * *$ & $-2.6 * * *$ & $-2.1 * * *$ \\
\hline MS25 & $-6.2 * * *$ & $-0.3 * *$ & $1.6 * * *$ \\
\hline MS3 & $-29.1 * * *$ & $-2.7 * * *$ & $-3.6 * * *$ \\
\hline MS4 & $-13.8 * * *$ & $-1.0 * * *$ & $6.1 * * *$ \\
\hline MS5 & $-31.4 * * *$ & $-2.0 * * *$ & $-2.1 * * *$ \\
\hline MS6 & $-42.7 * * *$ & $-2.6 * * *$ & $-2.8 * * *$ \\
\hline MS7 & $-43.9 * * *$ & $-2.7 * * *$ & $-2.0 * * *$ \\
\hline MS8 & $-16.8 * * *$ & $-1.6 * * *$ & -0.2 \\
\hline MS9 & $-14.5 * * *$ & $-0.7 * * *$ & $1.0 * *$ \\
\hline Type of inspection & YES & YES & YES \\
\hline Type of vessel & YES & YES & YES \\
\hline Age at inspection & YES & YES & YES \\
\hline Vessel flag & YES & YES & YES \\
\hline Number of observations & 32,206 & 32,206 & 32,206 \\
\hline
\end{tabular}

Source: data from the EU Region MoU 2014-2015, authors' calculations.

Note: estimates from linear probability and linear regression models. Significance levels are $1 \%\left({ }^{* * *}\right)$, $5 \%(* *)$ and $10 \%(*)$.

Estimates show that almost all country of inspection fixed effects are statistically significant at the 1 percent level. This means that, net of the type of inspection and of vessel characteristics (type, age, flag), there are still differences across countries of inspection, a result similar to $[16,17]$. Turning to the likelihood of having at least one deficiency detected (column 1, Table 2), all marginal effects are negative. This implies that the probability for a vessel of having at least one deficiency

\footnotetext{
${ }^{13}$ Detailed results for all covariates with coefficients, t-values and marginal effects are available from the authors upon request.
} 
detected is higher when the inspection is carried out in MS1. The gap is impressive for some countries. Compared to MS1, the probability of having a vessel without deficiency is more than 40 percentage points lower in MS6, MS7, MS12, MS20 and MS24.

Similar results are found for the number of deficiencies (column 2, Table 2). Compared to MS1, inspections completed in MS3, MS6, MS7, MS12, MS18 or MS24 are associated with less deficiencies (with a gap exceeding 2.5 deficiencies per vessel). The situation is different for detention (column 3, Table 2). Compared to the reference country MS1, the probability of having a vessel detained increases by 6.1 percentage points when the vessel is inspected in MS4 and by 3.3 percentage points in MS14. Conversely, detention decreases by 4.8 percentage points when the vessel is inspected in MS2 and by 3.6 when inspected in MS3.

The comparison of the three PSC outcomes (DEF, DET, DEFN) shows that there is an impact from being inspected in a country instead of another, though there is no clear hierarchy. On the one hand, some countries such as MS10, MS19 or MS25 rank higher compared to MS1 in terms of all three PSC outcomes. Specifically, MS19 ranks third in terms of any deficiency, it ranks first in terms of number of deficiencies and it ranks fifth in terms of detention. Differently, MS11 ranks $18^{\text {th }}$ in terms of any deficiency and number of deficiencies but it is ranks second for detention. If these empirical findings confirm the first hypothesis on PSC country differences, both in number of deficiencies and in rates of detention, they also confirm that vessels' characteristics impact PSC outcomes. The $\mathrm{R}^{2}$ associated to the model explaining the probability of having any deficiency is more than three times higher with both vessels' characteristics and inspection country dummies $\left(R^{2}=0.221\right)$ than with country dummies only $\left(R^{2}=0.065\right)$. The same ratio is around 4.3 both for number of deficiencies and detention. As expected, vessels' characteristics are the most important factor explaining the PSC outcomes.

For instance, age is positively related to deficiencies or detention. Compared to the reference age category which is less than 5 years old, the probability of having a vessel detained increases by 4.7 percentage points when the vessel is more than 30 years old, and by 2.1 percentage points for the number of deficiencies. Also, Passenger 
and Ro-Ro vessels are subject to less detention and deficiencies compared to the "other vessels" category, while general cargo are more often detained and with more deficiencies detected.

\section{Number of inspectors}

This subsection investigates whether the number of inspectors allocated to carry out an inspection could explain the cross-country differences identified in the previous section and in former studies $[16,17]$. As reported in Figure 3 , there are indeed large disparities in the number of inspectors mobilized for an inspection. For the whole sample, more than one-half of inspections (56.8\%) were carried out using one inspector. They are two for $36.9 \%$ of inspections and three and more for $6.3 \%$ of inspections.

More inspectors are mobilized for more detailed and expanded inspections. The proportion of inspections with exactly two inspectors is $31.4 \%$ for initial inspections, $37.3 \%$ for more detailed inspections and $47.5 \%$ for expanded expansions. The decision of engaging one or more inspectors on board is not part of the EU legislation and is a sovereign decision remaining in each individual member state. This flexibility may be positive since MSs are in a position to allocate the number of inspectors on the foundation of financial circumstances, personnel and territorial extension.

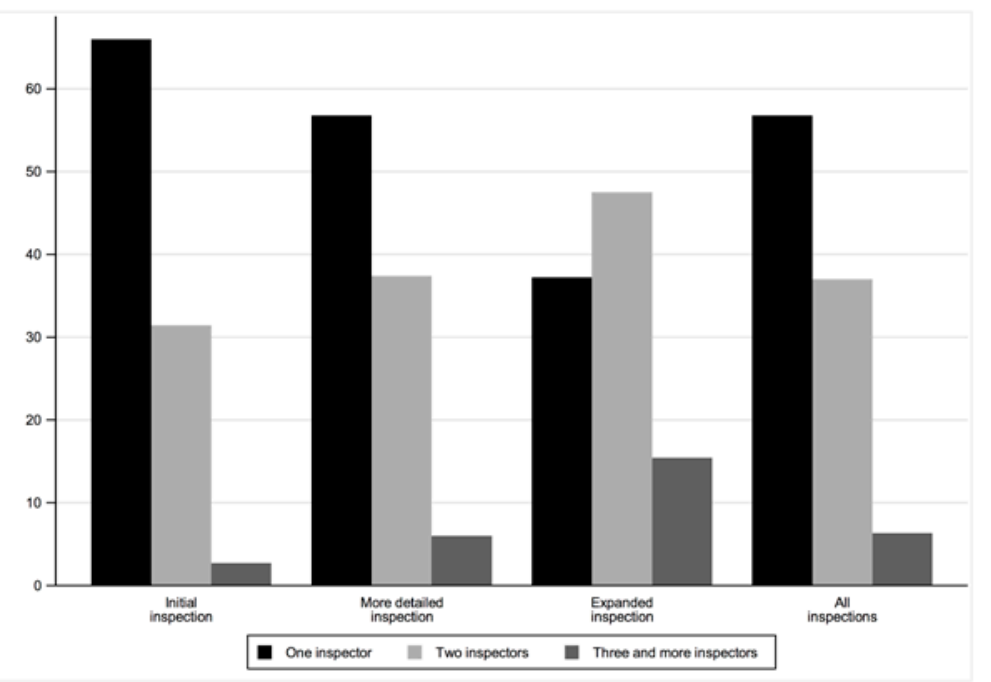

Figure 3. Number of inspectors, by type of inspection

Source: data from the EU Region MoU 2014-2015, authors' calculations. 
Figure 4 shows some statistics on the average number of inspectors per inspection for each member country and by type of inspection. These averages are calculated because of the correlation between the number of inspectors and the type of inspection evidenced in Figure 3. Again, there are large differences by country. For initial inspections, the average number of inspectors per inspection ranges from 1.0 in MS16 and MS20 to 1.8 in MS8 and 2.1 in MS2. Almost the same rankings are found for more detailed inspections, with the lowest averages in MS20 (1.0) and MS16 (1.1) and the highest averages in MS8 (1.9) and MS2 (2.2). For expanded inspections, the highest average numbers of inspectors are found in MS8 (2.4), MS4 (2.6) and MS7 (2.7) and the lowest are still in MS16 (1.1) and MS20 (1.1).
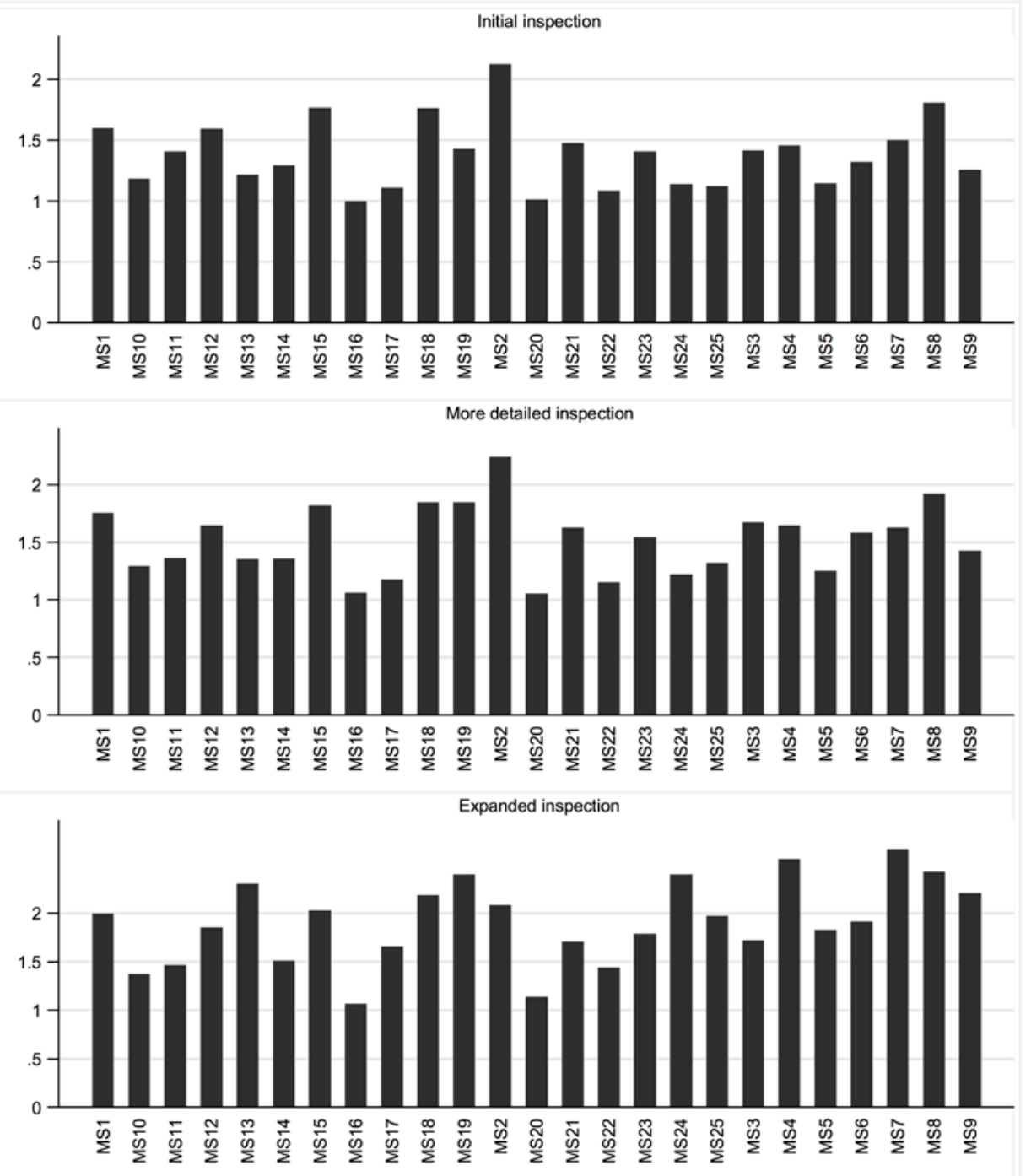

Figure 4. Number of inspectors per inspection, by member country and type of inspection Source: data from the EU Region 2014-2015, authors' calculations. 
The number of inspectors is likely to influence the PSC outcomes. A higher number of inspectors affords the inspection of more specific areas within the same amount of time spent on board the ship. For instance, a single inspector with a deck background might spend 20 minutes inspecting the navigation bridge and life-saving appliances and then another 20 minutes to sweep through the engine room, cargo spaces, and marine pollution prevention related logs and records. On the other hand, a team of three inspectors could concentrate the same 40 minutes on only one or two specific areas. This invariably leads to closer examinations and therefore higher probabilities for noting deficiencies and even ordering detentions.

Figure 5 confirms the relevance of such an assumption. The mean number of deficiencies detected is 4.6 when three or more inspectors are mobilized against 2.8 when there are two inspectors and 1.9 when there is only one. The gap is even larger when examining the impact on the detention rate, which is $13.8 \%$ with three inspectors against $4.3 \%$ for two inspectors and $1.7 \%$ for one. Interpreting these results remains nonetheless difficult as they may be subject to the issue of reverse causality. As explained above, the decision to dispatch one or more inspectors on board depends on the MS according to the travelling distance from the office to the port, the internal organization of the maritime administration, the national policy and the size of the vessel, among other reasons. 

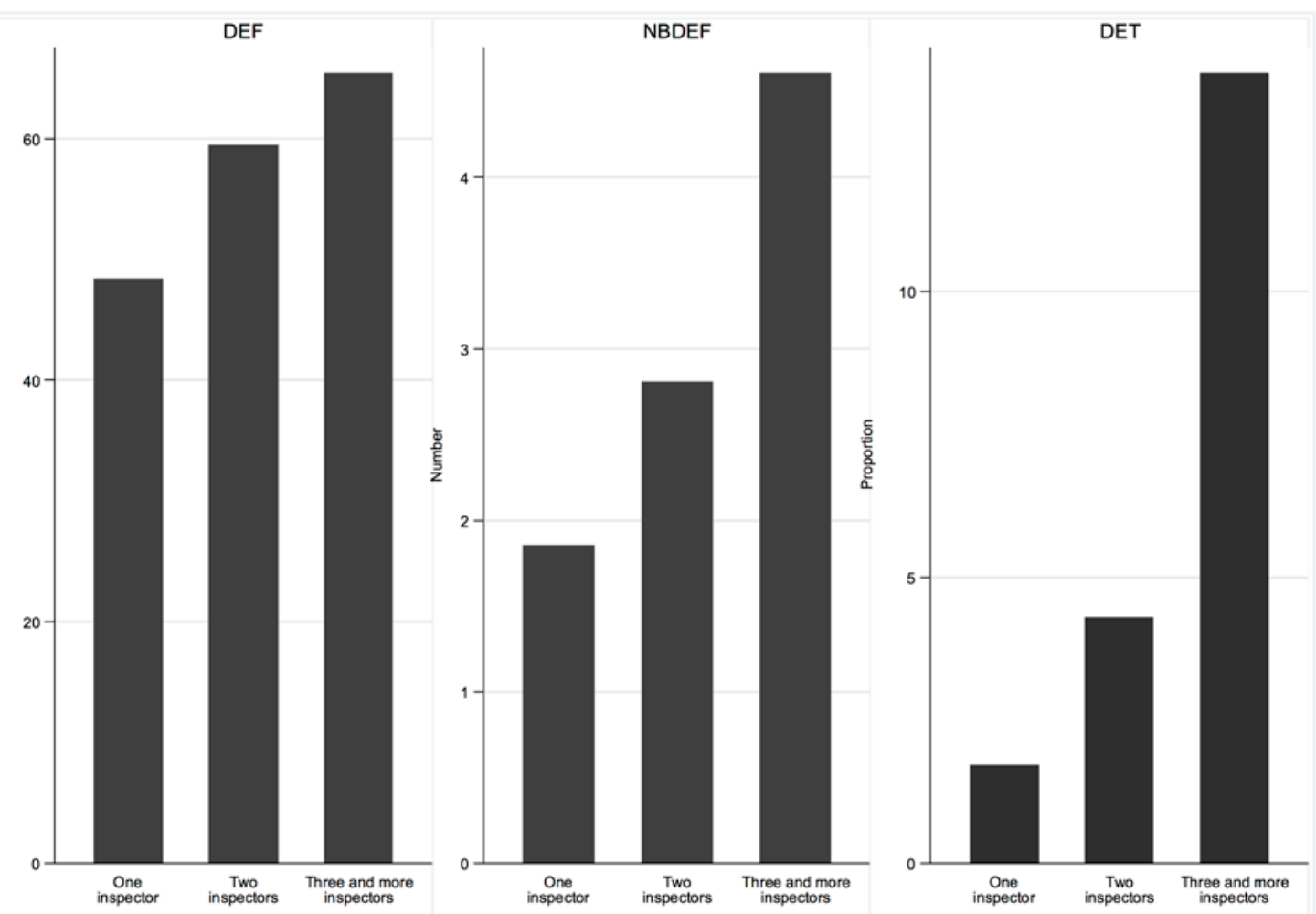

Figure 5. Results of inspection, by number of inspectors

Source: data from the EU Region 2014-2015, authors' calculations.

Table 3 assesses whether the number of inspectors has an influence on PSC outcomes once vessel characteristics are introduced as explanatory variables in the various regressions. When considering the whole sample of inspections (panel A), the probability of having any deficiencies is 8.8 percentage points higher when there are two inspectors rather than one and even 13.4 percentage points with three inspectors. In the same vein, the probability of having a vessel detained is 3.8 percentage points higher with two inspectors (rather than one) and 14.0 percentage points with three inspectors. Detailed results per type of inspection confirm the positive correlation between the number of inspectors and the PSC outcomes, with large marginal effects for detention.

Table 3. Marginal effect of number of inspectors on inspection results

\begin{tabular}{llll}
\hline Variables & $D E F$ (in \%) & \multicolumn{1}{c}{$D E F N$} & $D E T$ (in \%) \\
\hline A. All inspections $(N=32,206)$ & & Ref & Ref \\
One inspector & Ref & $1.0^{* * *}$ & $3.8^{* * *}$ \\
Two inspectors & $8.8^{* * *}$ & $2.7^{* * *}$ & $14.0^{* * *}$ \\
Three and more inspectors & $13.4^{* * *}$ & YES & YES \\
Controls & YES & & \\
B. Initial inspections $(N=10,076)$ & & Ref & \\
One inspector & Ref & $0.3^{* * *}$ & \\
Two inspectors & $8.9^{* * *}$ & $0.2^{* *}$ & \\
Three and more inspectors & $6.0^{* *}$ & &
\end{tabular}


Controls

C. More detailed inspections $(N=17,431)$

One inspector

Two inspectors

Three and more inspectors

Vessel characteristics

D. Expanded inspections $(N=4,699)$

One inspector

Two inspectors

Three and more inspectors

Controls

$\begin{array}{lll}\text { YES } & \text { YES } & \text { YES } \\ \text { Ref } & \text { Ref } & \text { Ref } \\ 8.4^{* * *} & 1.3^{* * *} & 5.7^{* * *} \\ 16.5^{* * *} & 3.9^{* * *} & 21.0^{* * *} \\ \text { YES } & \text { YES } & \text { YES } \\ & & \\ \text { Ref } & \text { Ref } & \text { Ref } \\ 11.4^{* * *} & 1.3^{* * *} & 4.5^{* * *} \\ 14.1^{* * *} & 2.6^{* * *} & 11.2^{* * *} \\ \text { YES } & \text { YES } & \text { YES }\end{array}$

Source: data from the EU Region 2014-2015, authors' calculations.

Note: estimates from linear probability and linear regression models. Significance levels are $1 \%(* * *)$, $5 \%\left({ }^{* *}\right)$ and $10 \%\left({ }^{*}\right)$. Each regression also includes type of inspection, type of vessel, age at inspection, vessel flag and state of inspection as explanatory variables.

The results are in line with the second hypothesis as well as with former studies. In their study on the Spanish Maritime Administration, Ravira and Piniella [41] strongly advocated for multidisciplinary teams on board given the enhanced likelihood of detecting deficiencies as well as a more efficient decision-making process. Nevertheless, it is clear that the data obtained does not provide any information on the time and effort spent by each inspector during each inspection. So, at that stage, it can only be concluded that the number of inspectors assigned to each inspection is one element explaining the country differences in PSC outcomes observed in our data. However, the study is not able to explain through which mechanisms this effect operates.

\section{Background of inspectors}

As the database includes an inspector identifier, additional information on the educational background of the 845 inspectors involved in the 32,206 inspections was collected through the questionnaire that each MS fills in during the preparatory phase of the five years' cycle of visits. Those visits monitor compliance and performance of MSs with regard to the PSC Directive [11] following the provisions of Article 30. There are 24 initial different educational backgrounds that were grouped into the five following categories: seagoing (deck), seagoing (engine), architect/engineer, other university degrees, and others/unknown ${ }^{14}$.

\footnotetext{
${ }^{14}$ Information for 35 inspectors (4.1\% of inspectors) could not be obtained. The detailed categories are: Seagoing (deck); Seagoing (Radio Officer); Seagoing (Deck - Radio), Seagoing (engine); Naval Architect Seagoing (deck), Architect or engineer (Naval Architect: Naval Architect; Naval Engineer; Marine Engineer (MSc)), Other University (Law and Economics, the other Engineers not related to Maritime;
} 
Out of the 845 inspectors, $33.4 \%$ have a seagoing (deck) background, $23.4 \%$ have a seagoing (engine)_background, 11.2\% are architects or engineers, 19.1\% have another university degree and $12.9 \%$ are in the other/unknown category. At the country level, there exist large disparities in both the total number and background of inspectors. The average number of inspectors per country is 33.8 , with a standard deviation of 35.9. The number of inspectors ranges from 2 in MS16 to 120 in MS14. Five countries have 60 inspectors or more: MS10 with 65, MS8 with 93, MS23 with 106, MS25 with 100, and MS14 with 120. In MS14, $75.8 \%$ of inspectors have a university-related degree while those with the same background represent $17.0 \%$ in MS25. In that country, $40.0 \%$ of inspectors have a seagoing (deck) background against $2.5 \%$ in MS14.

To study the relationship between the inspector's background and the PSC outcomes, the data is transformed so that the unit level is now the inspector. In this new sample, a vessel inspected by two inspectors therefore contributes to two observations. This way, a sample of 48,636 individual inspections is obtained. Similar results are found for the proportion of vessels having any deficiencies and number of deficiencies, with little variation by inspector's background.

The number of deficiencies is for instance 2.6 for inspectors with seagoing (deck) background, 2.9 with seagoing (engine) background and 2.7 for architect or engineer. Concerning detention, the likelihood is somewhat higher for inspectors being either architects/engineers (5.6\%) or with other university background $(5.8 \%)$ than inspectors with seagoing (deck) background (3.8\%). At a more detailed level, inspectors with a background in either law or political sciences have a higher probability of being part of an inspection leading to a detention $(8.4 \%$ and $7.6 \%$, respectively).

Next, regression models are estimated to study the influence played by the inspector's background on PSC outcomes. Table 4 reports only marginal effects of the inspector's background ${ }^{15}$. For all outcomes, the background has in general a very small

\footnotetext{
Nautical Science; Nautical (University Degree); Nautical - Marine Technology (MSc) and Others (0 or unknown).

${ }^{15}$ The list of explanatory variables includes type of inspection, type of vessel, vessel age, flag of registry, country of inspection and number of inspectors when the vessel is inspected.
} 
effect in magnitude on the final PSC outcome. The largest effect on the number of deficiencies is for instance equal to 0.2 for initial inspections. When considering all inspections, the likelihood of having a vessel detained is higher when inspections are carried out by inspectors with a seagoing (engine) background (+0.5 percentage point) and by inspectors with a background of architect or engineer (1.0 percentage point). Those results are similar to Knapp and Franses [16] who estimated the probability of detention for inspectors with nautical background versus those with engineering background as oscillating between $1 \%$ and $3 \%$.

Table 4. Marginal effect of background of inspectors on inspection results

\begin{tabular}{|c|c|c|c|}
\hline Variables & $D E F$ (in \%) & $D E F N$ & $D E T$ (in \%) \\
\hline \multicolumn{4}{|c|}{ A. All inspections $(N=48,636)$} \\
\hline Seagoing (deck) & Ref & Ref & Ref \\
\hline Seagoing (engine) & $-1.7 * * *$ & -0.0 & $0.5^{* *}$ \\
\hline Architect or engineer & -0.8 & -0.0 & $1.0 * * *$ \\
\hline Other university & -1.2 & $-0.1^{*}$ & 0.2 \\
\hline Other or unknown & $2.0 * *$ & $0.1^{* *}$ & -0.1 \\
\hline Controls & YES & YES & YES \\
\hline \multicolumn{4}{|c|}{ B. Initial inspections $(N=13,787)$} \\
\hline Seagoing (deck) & Ref & Ref & \\
\hline Seagoing (engine) & $-3.9 * * *$ & $-0.1 * * *$ & \\
\hline Architect or engineer & 0.4 & 0.0 & \\
\hline Other university & $-2.9 *$ & $-0.1 * *$ & \\
\hline Other or unknown & 1.8 & $0.2^{* * *}$ & \\
\hline Controls & YES & YES & \\
\hline \multicolumn{4}{|c|}{ C. More detailed inspections $(N=26,196)$} \\
\hline Seagoing (deck) & Ref & Ref & Ref \\
\hline Seagoing (engine) & $-1.1^{*}$ & 0.0 & 0.4 \\
\hline Architect or engineer & $-2.1 * *$ & -0.1 & $1.0^{*}$ \\
\hline Other university & -1.5 & -0.1 & 0.2 \\
\hline Other or unknown & $1.9 *$ & 0.1 & -0.4 \\
\hline Vessel characteristics & YES & YES & YES \\
\hline \multicolumn{4}{|c|}{ D. Expanded inspections $(N=8,653)$} \\
\hline Seagoing (deck) & Ref & Ref & Ref \\
\hline Seagoing (engine) & -1.2 & -0.1 & 0.4 \\
\hline Architect or engineer & 0.4 & -0.0 & $1.8^{*}$ \\
\hline Other university & 1.3 & -0.0 & 0.3 \\
\hline Other or unknown & $3.0^{*}$ & -0.0 & -0.3 \\
\hline Controls & YES & YES & YES \\
\hline
\end{tabular}

Source: data from the EU Region 2014-2015, authors' calculations.

Note: estimates from linear probability and linear regression models. Significance levels are $1 \%(* * *)$, $5 \%(* *)$ and $10 \%(*)$. Each regression also includes type of inspection, type of vessel, age at inspection, vessel flag and state of inspection as explanatory variables.

A last concern is whether the background of inspectors has an influence on the type of deficiencies registered during the inspection. As shown in the last column of Table 5, the most frequent deficiencies are related to certificate and documentation (15.8\% of total deficiencies), fire safety (14.0\%), safety of navigation (12.3\%) and labor 
conditions (10.2\%). A Chi ${ }^{2}$ test shows that the type of deficiencies and the background of inspectors are not independent. For instance, inspectors with either a seagoing (deck) or seagoing (engine) background report more often deficiencies related to safety or navigation. The reverse pattern is found for inspectors being either architect or engineer or having other university diploma. Architects or engineers more often report deficiencies related to labor conditions, while inspectors from other university backgrounds more often report deficiencies related to certificate and documentation.

Table 5. Type of deficiencies by background of inspectors

\begin{tabular}{|c|c|c|c|c|c|c|}
\hline \multirow[t]{2}{*}{ Type of deficiencies } & \multicolumn{5}{|c|}{ Background of inspectors } & \multirow{2}{*}{$\begin{array}{l}\text { Proportion } \\
\text { (in \%) }\end{array}$} \\
\hline & $\begin{array}{l}\text { Seagoing } \\
\text { (deck) }\end{array}$ & $\begin{array}{l}\text { Seagoing } \\
\text { (engine) }\end{array}$ & $\begin{array}{l}\text { Architect or } \\
\text { engineer }\end{array}$ & $\begin{array}{l}\text { Other } \\
\text { university }\end{array}$ & $\begin{array}{l}\text { Other or } \\
\text { unknown }\end{array}$ & \\
\hline Certificate and documentation & 15.4 & 15.1 & 16.4 & 17.7 & 16.1 & 15.8 \\
\hline Fire safety & 14.3 & 13.1 & 12.7 & 14.9 & 15.8 & 14.0 \\
\hline Safety of Navigation & 13.1 & 13.3 & 10.0 & 10.2 & 11.1 & 12.3 \\
\hline Labour conditions & 9.9 & 9.1 & 12.1 & 10.3 & 12.4 & 10.2 \\
\hline Life saving appliances & 8.8 & 8.5 & 7.3 & 8.4 & 9.0 & 8.5 \\
\hline Emergency systems & 4.9 & 5.2 & 6.2 & 6.1 & 5.9 & 5.4 \\
\hline Pollution prevention & 4.9 & 5.4 & 5.9 & 5.3 & 4.7 & 5.2 \\
\hline Living and working conditions & 5.2 & 6.3 & 3.8 & 4.8 & 2.9 & 5.1 \\
\hline Propulsion and auxiliary machinery & 4.5 & 5.5 & 5.6 & 4.0 & 4.6 & 4.9 \\
\hline Structural conditions & 4.6 & 4.4 & 5.0 & 4.0 & 4.7 & 4.5 \\
\hline ISM & 4.3 & 4.3 & 4.4 & 5.0 & 4.2 & 4.4 \\
\hline Water/weathertight conditions & 4.4 & 4.4 & 4.6 & 4.1 & 3.7 & 4.3 \\
\hline Radio communications & 2.5 & 2.4 & 2.5 & 1.7 & 2.1 & 2.3 \\
\hline Alarms & 1.0 & 1.3 & 0.9 & 0.9 & 0.8 & 1.1 \\
\hline ISPS & 0.6 & 0.6 & 0.8 & 1.2 & 0.7 & 0.7 \\
\hline Other & 0.8 & 0.6 & 1.0 & 0.5 & 0.9 & 0.7 \\
\hline Cargo operations including equipment & 0.5 & 0.3 & 0.5 & 0.6 & 0.3 & 0.4 \\
\hline Dangerous goods & 0.2 & 0.2 & 0.3 & 0.3 & 0.2 & 0.2 \\
\hline
\end{tabular}

Source: data from the EU Region 2014-2015, authors' calculations.

Table 6 shows the estimated probability for an inspector to report a given type of deficiency ${ }^{16}$. Again, linear probability models are used to take into account the role of vessel characteristics. When the country of inspection is not controlled for (panel A), some significant impacts related to the background of inspectors (other or unknown backgrounds being the reference category) are found. For instance, deficiencies related to certificates and documentation are more likely for inspectors with a background from other university. Deficiencies related to safety of navigation are more frequent when inspectors have a background in seagoing (deck) or seagoing (engine).

\footnotetext{
${ }^{16}$ The focus is restricted to the 10 most frequently reported types of deficiencies.
} 
However, these results are not any longer significant when the country of inspection is controlled for (panel B). The results which are consistent across panel $A$ and $B$ are related to fire safety-related deficiencies which are less likely for inspectors with a university degree, labor conditions-related deficiencies which are less likely for inspectors with a nautical background while living and working conditions-related deficiencies are more likely for these inspectors. Finally, as expected, inspectors with a seagoing (engine) background are more likely to detect propulsion and auxiliary machinery-related deficiencies.

It is clear that, beside their background, PSCOs may be influenced by bureaucratic and cultural practices in their country, the extent of their training, the administrative and political support of their administration among other factors already discussed in the literature.

\section{Concluding comments and policy implications}

The rise of the various memoranda of understanding since 1982 has set the ambitious aim of harmonising the enforcement standards within the region where the MoU was established [42]. However, the limits and complexity faced trying to achieve this goal has been highlighted by several publications in the past thirty years $[2,4,10$, $14,17,22,38,39,43]$. Taking as a reference the EU region, the purpose of this paper was to determine whether single EU countries record a higher number of deficiencies and or detention net of the characteristics of the vessel inspected. Also, an attempt was made to determine whether discrepancies in the output of an inspection are influenced either by the team composition at the time of the inspection or by the background of the PSCOs.

With regard to the first aspect, results have made clear that some of the differences in terms of detecting at least one deficiency and/or detaining a vessel are significant with some MSs showing a probability $40 \%$ lower of reporting zero deficiencies compared to others. Such findings raise doubts on whether the establishment of harmonised procedures on inspection and detention, as stated in the Article 1 of the EU Directive on PSC [11], is being achieved. 
Table 6. Linear probability estimates of the main type of deficiencies

\begin{tabular}{|c|c|c|c|c|c|c|c|c|c|c|}
\hline Variables & $\begin{array}{l}\text { Certificate } \\
\text { and } \\
\text { documentati } \\
\text { on }\end{array}$ & Fire safety & $\begin{array}{l}\text { Safety of } \\
\text { navigation }\end{array}$ & $\begin{array}{l}\text { Labour } \\
\text { conditions }\end{array}$ & $\begin{array}{l}\text { Life saving } \\
\text { appliances }\end{array}$ & $\begin{array}{l}\text { Emergency } \\
\text { systems }\end{array}$ & $\begin{array}{l}\text { Pollution } \\
\text { prevention }\end{array}$ & $\begin{array}{l}\text { Living and } \\
\text { working } \\
\text { conditions }\end{array}$ & $\begin{array}{l}\text { Propulsion } \\
\text { and auxiliary } \\
\text { machinery }\end{array}$ & $\begin{array}{l}\text { Structural } \\
\text { conditions }\end{array}$ \\
\hline \multicolumn{11}{|l|}{ Panel A. No control of MS } \\
\hline Seagoing (deck) & -0.8 & $-1.4 * * *$ & $1.9 * * *$ & $-2.5 * * *$ & -0.1 & $-0.8 * * *$ & 0.2 & $2.3 * * *$ & -0.3 & -0.0 \\
\hline Seagoing (engine) & $-0.8^{*}$ & $-2.3^{* * *}$ & $2.0 * * *$ & $-3.5^{* * *}$ & -0.4 & $-0.7^{* *}$ & $0.9 * * *$ & $3.2^{* * *}$ & $0.8 * * *$ & -0.2 \\
\hline Architect or engineer & -0.3 & $-3.2 * * *$ & $-1.0 * *$ & -0.1 & $-1.6 * * *$ & 0.5 & $1.2 * * *$ & $1.1^{* * *}$ & $0.9 * *$ & 0.3 \\
\hline Other university & $2.0 * * *$ & $-1.2^{* *}$ & -0.7 & $-2.1 * * *$ & -0.5 & 0.1 & $0.6 * *$ & $1.8 * * *$ & $-0.8 * * *$ & $-0.7^{* * *}$ \\
\hline Other or unknown & Ref & Ref & Ref & Ref & Ref & Ref & Ref & Ref & Ref & Ref \\
\hline Country of inspection MS & NO & NO & NO & NO & NO & NO & NO & NO & NO & NO \\
\hline Controls & YES & YES & YES & YES & YES & YES & YES & YES & YES & YES \\
\hline \multicolumn{11}{|l|}{$\begin{array}{l}\text { Panel B. Control of MS } \\
\text { Inspector's background }\end{array}$} \\
\hline Seagoing (deck) & $0.8^{*}$ & -0.3 & 0.0 & $-1.7 * * *$ & 0.3 & -0.0 & -0.3 & $0.6^{* *}$ & -0.4 & -0.1 \\
\hline Seagoing (engine) & -0.2 & -0.1 & $-0.8^{* *}$ & $-1.5^{* * *}$ & 0.2 & 0.2 & 0.1 & $0.5^{*}$ & $1.0^{* * *}$ & -0.0 \\
\hline Architect or engineer & -0.6 & -0.7 & $-1.2 * * *$ & -0.6 & -0.6 & 0.3 & $1.0 * * *$ & $1.2^{* * *}$ & -0.1 & 0.2 \\
\hline Other university & 0.6 & $-2.2 * * *$ & -0.2 & $1.0^{* *}$ & 0.3 & -0.5 & 0.2 & 0.0 & $-0.8^{* *}$ & -0.2 \\
\hline Other or unknown & Ref & Ref & Ref & Ref & Ref & Ref & Ref & Ref & Ref & Ref \\
\hline Country of inspection MS & YES & YES & YES & YES & YES & YES & YES & YES & YES & YES \\
\hline Controls & YES & YES & YES & YES & YES & YES & YES & YES & YES & YES \\
\hline Number of observations & 131,039 & 131,039 & 131,039 & 131,039 & 131,039 & 131,039 & 131,039 & 131,039 & 131,039 & 131,039 \\
\hline
\end{tabular}

Source: data from the EU Region 2014-2015, authors' calculations.

Note: estimates from linear probability models. Significance levels are $1 \%\left({ }^{* * *}\right), 5 \%(* *)$ and $10 \%(*)$. Each regression also includes type of inspection, type of vessel, age at inspection, vessel flag and state of inspection as explanatory variables. 
Moreover, the results enable policy makers to flag those countries which are struggling with the implementation process of harmonised standards and, in view of reviewing the 2009/16/EC, ascertain overhaul strategies.

Considering the team composition element in the inspection process, the results confirm, at the European Union level, the findings of previous studies [40,41]. The analysis clearly shows that the likelihood of detecting deficiencies and detaining vessels is higher if the number of inspectors on board is more than one. Finally, the extent to which inspectors report certain types of deficiencies according to their background is investigated, as suggested already by some authors [16, 40, 41]. While the significance is not always consistent, it is clear that some backgrounds are more likely to detect certain types of deficiencies. For example, inspectors with a seagoing (engine) background are more likely to detect propulsion and auxiliary machinery deficiencies compared to other inspectors.

A potential drawback of this study is that it sheds light on correlations between the role of inspectors and PSC outcomes. As previously emphasized, the interpretation of some results is subject to reverse causality issues. If for instance two or three inspectors are systematically chosen when vessels are presumed to be in bad conditions, then the positive correlation between the number of inspectors and the number of deficiencies sounds obvious. What matters is knowing whether choosing ex ante a higher number of inspectors increases in a causal way the number of deficiencies during the inspection or whether assigning an inspector with some specific background indeed leads to a higher number of reported deficiencies.

A simple empirical strategy to further examine the relevance of causal effects is to turn to randomized experiments. Starting from a list of vessels to be inspected, a randomized allocation of either the number of inspectors (either one, or two, or three) or the background of inspectors would provide the ideal framework. Once inspectors are randomly selected, then a comparison of the PSC outcomes between different groups of vessels (those being inspected by one inspector only versus those being inspectors by exactly two inspectors for instance) will provide the causal effect of the number of inspectors. Such random experiments can certainly be implemented at low cost by port authorities and would provide very useful information. 
In conclusion, discrepancies in harmonisation have been encountered. In the first part, differences across MSs have raised doubts encompassing the PSC system as a whole. However, particular attention should be given to some neglected areas such as team composition and inspectors' background. Despite the valid grounds for an arbitrary team composition by MSs, the harmonisation of such process should be considered in future policy considerations. These results would benefit any policy study that might consider recommending a review of Directive 2009/16/EC.

\section{Acknowledgments}

The authors would like to thank the reviewer for very helpful comments and suggestions on a previous draft, all the institutions that have participated in this study for their assistance and know-how, and EMSA and the European Commission for providing further insights and information. The views presented in the paper are the authors' own opinions.

\section{Funding}

This work was supported by the European Commission and the SAFEPEC project [grant number FP7-SST-2013-RTD-4-2. 605081]. 


\section{References}

[1] O. Özçayır, Port state control, 2nd ed., LLP, London, 2004.

[2] M. Bloor, R. Datta, Y. Gilinskiy, T. Horlick-Jones, Unicorn among the Cedars: On the Possibility of Effective 'Smart Regulation' of the Globalized Shipping Industry, Social \& Legal Studies 15(4) (2006) 534-551. doi: 10.1177/0964663906069546

[3] D. Anderson, The Roles of Flag States, Port States, Coastal States and International Organisations in the Enforcement of International Rules and Standards Governing the Safety of Navigation and the Prevention of Pollution from Ships under the UN Convention on the Law, Singapore Journal of International \& Comparative Law 2 (1998) 557-578. doi:

[4] O. Özçayır, The Use of Port State Control in Maritime Industry and Application of the Paris MoU, Ocean and Coastal Law Journal 14(2) (2009) 201-239. doi:

[5] J. van Leeuwen, The regionalization of maritime governance: Towards a polycentric governance system for sustainable shipping in the European Union, Ocean \& Coastal Management 117 (2015) 23-31. doi: http://dx.doi.org/10.1016/j.ocecoaman.2015.05.013 [6] E.J. Molenaar, Port State Jurisdiction: Toward Comprehensive, Mandatory and Global Coverage, Ocean Development \& International Law 38(1-2) (2007) 225-257. doi: 10.1080/00908320601071520

[7] D. Bell, Port state control v flag state control: UK government position, Marine Policy 17(5) (1993) 367-370. doi: 10.1016/0308-597X(93)90049-9

[8] Ademuni-Odeke, Port State Control and UK Law, Journal of Maritime Law \& Commerce 28(4) (1997) 657-666. doi:

[9] E.J. Molenaar, B. Pons, The EC Directive on Port State Control in Context, The International Journal of Marine and Coastal Law 11(2) (1996) 241-288. doi: 10.1163/157180896X00122

[10] T. Keselj, Port State Jurisdiction in Respect of Pollution from Ships: The 1982 United Nations Convention on the Law of the Sea and the Memoranda of Understanding, Ocean Development \& International Law 30(2) (1999) 127-160. doi: 10.1080/009083299276212

[11] European Parliament and the Council, DIRECTIVE 2009/16/EC OF THE EUROPEAN PARLIAMENT AND OF THE COUNCIL of 23 April 2009 on port State control Strasbourg, France, 2009.

[12] F. Plaza, Port State Control: Towards Global Standardisation, Maritime Studies 1994(75) (1994) 28-34. doi: 10.1080/07266472.1994.10878379

[13] D. Anderson, The Effect of Port State Control on Substandard Shipping, Maritime Studies (125) (2002) 20-25. doi: 10.1080/07266472.2002.10878678

[14] O.F. Knudsen, B. Hassler, IMO legislation and its implementation: Accident risk, vessel deficiencies and national administrative practices, Marine Policy 35 (2011) 201207. doi: 10.1016/j.marpol.2010.09.006

[15] H.-S. Bang, D.-J. Jang, Recent Developments in Regional Memorandums of Understanding on Port State Control, Ocean Development \& International Law 43(2) (2012) 170-187. doi: 10.1080/00908320.2012.672293

[16] S. Knapp, P.H. Franses, A global view on port state control: econometric analysis of the differences across port state control regimes, Maritime Policy \& Management 34(5) (2007) 453-482. doi: 10.1080/03088830701585217

[17] P. Cariou, M.Q. Mejia, F.-C. Wolff, Evidence on target factors used for port state control inspections, Marine Policy 33(5) (2009) 847-859. doi: 10.1016/j.marpol.2009.03.004 
[18] A. Blanco-Bazán, IMO - Historical highlights in the life of a UN Agency, Journal of the History of International Law 6(2) (2004) $259-283$. doi: $10.1163 / 1571805042782118$

[19] P.B. Payoyo, Implementation of international conventions through port state control: an assessment, Marine Policy 18 (1994) 379-392. doi: 10.1016/0308597X(94)90034-5

[20] M. Cuttler, Incentives for Reducing Oil Pollution from Ships: The Case for Enhanced Port State Control, Environmental Law Review 8(1) (1995) 175-206. doi:

[21] H.-S. Bang, Is Port State Control an Effective Means to Combat Vessel-Source Pollution? An Empirical Survey of the Practical Exercise by Port States of Their Powers of Control, The International Journal of Marine and Coastal Law 23(4) (2008) 715-759. doi: 10.1163/157180808X353911

[22] J. Mansell, Port state control in the Asia-Pacific region: Issues and challenges, Australian Journal of Maritime and Ocean Affairs 1 (2009) 73-87. doi:

[23] P. Cariou, M.Q. Mejia, F.-C. Wolff, On the effectiveness of port state control inspections, Transportation Research Part E: Logistics and Transportation Review 44(3) (2008) 491-503. doi: 10.1016/j.tre.2006.11.005

[24] P. Cariou, M.Q. Mejia, F.-C. Wolff, An econometric analysis of deficiencies noted in port state control inspections, Maritime Policy \& Management 34(3) (2007) 243-258. doi: 10.1080/03088830701343047

[25] P. Cariou, F.-C. Wolff, Do Port State Control Inspections Influence Flag - and Class-hopping Phenomena in Shipping?, Journal of Transport Economics and Policy 45(2) (2011) 155-177. doi:

[26] G.E. Bijwaard, S. Knapp, Analysis of ship life cycles-The impact of economic cycles and ship inspections, Marine Policy 33 (2009) 350-369. doi: 10.1016/j.marpol.2008.08.003

[27] C. Heij, G.E. Bijwaard, S. Knapp, Ship inspection strategies: Effects on maritime safety and environmental protection, Transportation Research Part D: Transport and Environment 16 (2011) 42-48. doi: 10.1016/j.trd.2010.07.006

[28] S. Knapp, P.H. Franses, Econometric analysis on the effect of port state control inspections on the probability of casualty, Marine Policy 31 (2007) 550-563. doi: 10.1016/j.marpol.2006.11.004

[29] S. Knapp, P.H. Franses, Econometric analysis to differentiate effects of various ship safety inspections, Marine Policy 32 (2008) 653-662. doi: 10.1016/j.marpol.2007.11.006

[30] T.L. McDorman, Port State Enforcement: A Comment on Article 218 of the 1982 Law of the Sea Convention, Journal of Maritime Law \& Commerce 28(2) (1997) 305322. doi:

[31] H.-S. Bang, Port State Jurisdiction and Article 218 of the UN Convention on the Law of Sea,, Journal of Maritime Law \& Commerce 40(2) (2009) 291-313. doi:

[32] H.-S. Bang, Recommendations for Policies on Port State Control and Port State Jurisdiction., Journal of Maritime Law \& Commerce 44 (2013) 115-133. doi:

[33] R. Churchill, Port State Jurisdiction Relating to the Safety of Shipping and Pollution from Ships-What Degree of Extra-territoriality?, The International Journal of Marine and Coastal Law 31(3) (2016) 442-469. doi: 10.1163/15718085-12341409

[34] C. Ryngaert, H. Ringbom, Introduction: Port State Jurisdiction: Challenges and Potential, The International Journal of Marine and Coastal Law 31(3) (2016) 379-374. doi: 10.1163/15718085-12341405

[35] T.L. McDorman, Regional Port State Control Agreements: Some Issues Of International Law, Ocean \& Coastal Law Journal 5(2) (2000) 207-226. doi: 
[36] K.X. Li, H. Zheng, Enforcement of law by the Port State Control (PSC), Maritime Policy \& Management 35(1) (2008) 61-71. doi: 10.1080/03088830701848912

[37] J.E. Vorbach, The Vital Role of Non-Flag State Actors in the Pursuit of Safer Shipping, Ocean Development \& International Law 32(1) (2001) 27-42. doi: 10.1080/00908320150502186

[38] S. Knapp, M. van de Velden, Visualization of Differences in Treatment of Safety Inspections across Port State Control Regimes: A Case for Increased Harmonization Efforts, Transport Reviews 29 (2009) 499-514. doi: 10.1080/01441640802573749

[39] H. Sampson, M. Bloor, When Jack Gets out of the Box: The Problems of Regulating a Global Industry, Sociology 41(3) (2007) 551-569. doi: $10.1177 / 0038038507076623$

[40] A. Graziano, J.-U. Schröder-Hinrichs, A.I. Ölcer, After 40 years of regional and coordinated ship safety inspections: Destination reached or new point of departure?, Ocean Engineering $143 \quad$ (2017) 217-226. doi: http://dx.doi.org/10.1016/j.oceaneng.2017.06.050

[41] F.J. Ravira, F. Piniella, Evaluating the impact of PSC inspectors' professional profile: a case study of the Spanish Maritime Administration, WMU Journal of Maritime Affairs (2016) 1-16. doi: 10.1007/s13437-015-0096-y

[42] B. Marten, Port State Jurisdiction and the Regulation of International Maerchant Shipping, Cham, Switzerland, Springer, 2014.

[43] S. Knapp, P.H. Franses, A global view on port state control: econometric analysis of the differences across port state control regimes, Maritime Policy \& Management 34 (2007) 453-482. doi: 10.1080/03088830701585217 